\title{
Perencanaan Strategis SI/TI Dengan Metode Tozer Studi kasus SMK Bina Nusantara Ungaran
}

\author{
Galang Krisnawa Bhakti*1, Augie David Manuputty ${ }^{2}$ \\ 1,2 Universitas Kristen Satya Wacana /Program Studi Sistem Informasi; \\ Jl. Dr. O. Notohamidjojo Salatiga - Jawa Tengah, telp. 0298-321212 \\ e-mail : ${ }^{* 1} 682017048 @$ student.uksw.edu, ${ }^{2}$ augie.manuputty@uksw.edu
}

\begin{abstract}
Abstrak
Persaingan bisnis pada era informasi yang begitu cepat ini menjadi sangat ketat. Dengan demikian organisasi harus memiliki strategi bisnis yang sangat matang guna menghadapi persaingan tersebut. Penerapan sistem informasi serta teknologi menjadi salah satu strategi bisnis yang sangat berpengaruh untuk tetap dapat bertahan di dalam persaingan. Sistem informasi sangat dibutuhkan bagi dunia bisnis terutama di bidang pendidikan karena dapat mendukung proses operasional, mendukung keputusan, dan dapat meningkatkan kualitas pelayanan kepada masyarakat. SMK Bina Nusantara Ungaran merupakan salah satu institusi pendidikan yang sudah menerapkan sistem informasi serta teknologi, namun ternyata belum berjalan dengan optimal karena beberapa bagian belum menerapkan sistem informasi. Karena begitu pentingnya SI/TI bagi bidang pendidikan, di dalam penelitian ini akan membahas bagaimana merencanakan strategi SI/TI dengan metode versi Tozer dengan analisis pendukung seperti Value Chain Porter's, Five Force Porter's, SWOT, Critical Success Factor, dan McFarlan's Strategic Grid. Yang menghasilkan portofolio SI/TI yang selaras dengan visi dan misi guna mendukung proses bisnis yang dijalankan serta menjadikan SMK Bina Nusantara Ungaran unggul di bidang pendidikan.
\end{abstract}

Kata kunci -Perencanaan Strategis SI/TI, Metodologi Tozer, Value Chain, McFarlan's Strategic Grid

\begin{abstract}
Business competition in this fast information age has become very tight. Thus the organization must have a very mature business strategy in order to face this competition. The application of information systems and technology is one of the most influential business strategies in order to survive in the competition. Information systems are needed for the business world, especially in the field of education because they can support operational processes, support decisions, and can improve the quality of services to the community. SMK Bina Nusantara Ungaran is one of the educational institutions that has implemented an information system and technology, but it has not been running optimally because some parts have not implemented an information system. Because of the importance of IS / IT for education, this study will discuss how to plan an IS / IT strategy using the Tozer version of the method with supporting analysis such as Value Chain Porters, Five Force Porters, SWOT, Critical Success Factors, and McFarlan's Strategic Grid. Which produces an IS / IT portfolio that is in line with the vision and mission to support the business processes being carried out and makes SMK Bina Nusantara Ungaran superior in the field of education.
\end{abstract}

Keywords- IS / IT Strategic Planning, Tozer Methodology, Value Chain, McFarlan's Strategic Grid

\section{PENDAHULUAN}

Pada era informasi yang begitu cepat saat ini, setiap organisasi dituntut untuk dapat bersaing serta berinovasi dalam rangka meningkatkan keuntungan sebuah organisasi. Dengan demikian organisasi berbondong-bondong menerapkan sistem informasi dan teknologi informasi agar mendapatkan proses bisnis yang berjalan secara efektif dan efisien serta memberikan nilai tambah competitive advantage dalam persaingan bisnis [4]. Pendidikan merupakan salah satu bisnis yang bergerak dibidang jasa tidak terlepas dari dampak globalisasi serta penggunaan sistem informasi dan teknologi informasi di proses bisnisnya. Semakin banyaknya bisnis Pendidikan dengan berbagai bentuk 
sangat diperlukan resources yang baik, seperti dalam halnya mempromosikan organisasinya kepada konsumen dalam hal ini adalah siswa dan orang tua. Dengan demikian, perencanaan strategis SI/TI menjadi sangat penting.

Pengertian perencanaan strategis sistem informasi menurut Ward and Pepard adalah merupakan proses mengidentifikasi kebutuhan akan aplikasi sistem informasi berbasis komputer yang nantinya mendukung organisasi dalam melaksanakan rencana bisnis serta merealisasikan tujuan bisnisnya. Perencanaan strategis sistem informasi juga menjelaskan bagaimana alat, teknik, serta kerangka kerja dalam menyelaraskan strategi SI/TI dan strategi bisnis organisasi. [1]

Dalam melakukan perencanaan strategis sistem informasi ini akan digunakan metodologi Tozer, sehingga dapat dihasilkan sebuah model perencanaan strategis sistem informasi yang mendukung proses bisnis SMK Bina Nusantara serta menjawab kebutuhan SI/TI organisasi tersebut.

Penelitian mengenai perencanaan strategis sistem informasi dengan metodologi tozer cukup banyak dilakukan, seperti contoh pada penelitian pertama yang dilakukan oleh Andri Wijaya menyimpulkan bahwa mengidentifikasi serta menganalisa yang berhubungan maupun yang tidak berhubungan dengan inti bisnis perusahaan yang nantinya akan menghasilkan rekomendasi aplikasi untuk perusahaan. [3]

Penelitian kedua yang dilakukan oleh Andri dan Arif dengan menggunakan tools Five Forces Competitive Model, McFarlan Grid, analisa value chain, SWOT dan CSF (critical success factor). Yang akhirnya memiliki output yaitu portfolio aplikasi yang direncanakan guna menyelaraskan visi misi, tujuan dan proses bisnis perusahaan [4].

\section{METODE PENELITIAN}

Metodologi yang digunakan pada penelitian ini adalah metodologi perencanaan sistem informasi versi tozer. Metodologi ini jelas dan sederhana didalam menyampaikan rancangan strategi SI/TI [3][5] .Untuk metode pengambilan data peneliti menggunakan metode kualitatif dimana langkahlangkah yang diambil adalah berdasarkan wawancara, serta analisis lingkungan bisnis perusahaan, interpretasi data dan kesimpulan. kemudian tahapan tersebut akan menghasilkan portofolio perencanaan strategis sistem informasi [2]. Berikut penjelasan masing-masing tahapan pada gambar 2.

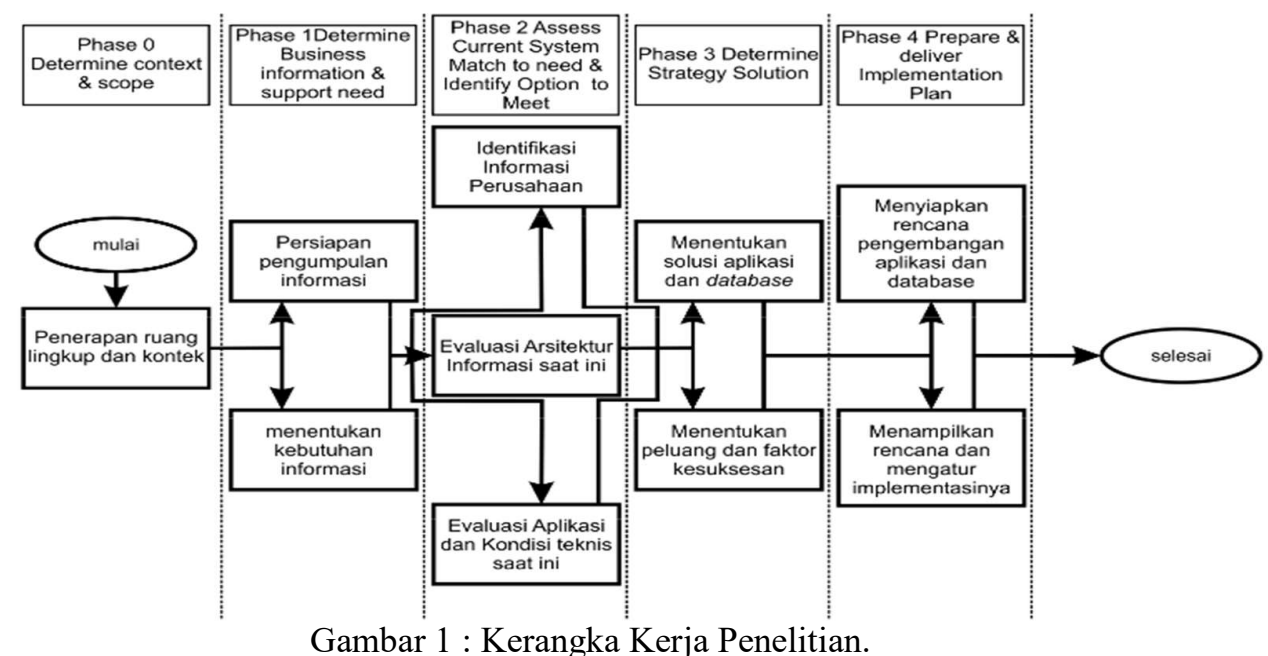

Menurut Tozer, arah dari pembuatan metodologi ini adalah : [2][7]

a. Menganalisa faktor-faktor yang mempengaruhi dalam kinerja organisasi atau perusahaan termasuk lingkungan bisnisnya.

b. Merumuskan dengan metode yang tepat dengan bisnis yang sudah ada.

c. Mengimplementasikan usulan serta proyek yang akan dijalankan.

d. Menggambarkan blok-blok dari rumusan perencanaan strategi dan aktifitas yang dijalankan. 
Didalam metodologi tozer ini memiliki tahapan masukkan maupun tahapan keluaran, Adapun tahapan masukkan meliputi :

a. Internal Organization: Meliputi faktor internal yang mempengaruhi bisnis seperti proses bisnis, visi misi, sumber daya, dan nilai bisnis.

b. External Factor Organization : Meliputi faktor eksternal yang mempengaruhi bisnis seperti, kondisi politik, ekonomi, sosial, dan persaingan bisnis.

c. Analysis IS/IT Organization : Meliputi tingkat kesiapan sistem, infrasturktur teknologi, sumber daya dan sudut pandang mengenai SI/TI didalam bisnis.

Adapun tahapan keluaran meliputi :

a. IS/IT Management Strategy : Meliputi strategi yang ditetapkan menyeluruh kemudian menjamin kebijakan yang konsisten pada saat dibutuhkan.

b. IS/IT Strategy : Meliputi kebijakan serta strategi untuk manajemen teknologi dan sumber daya.

\section{HASIL DAN PEMBAHASAN}

Dalam pembahasan penelitian ini maka dilakukan analisis dari hasil wawancara dan observasi yang mencakup kesesuaian sistem serta kebutuhan bisnis, yang berakhir menentukan solusi atau usulan sistem informasi. Berikut tahapan kerangka kerja penelitian yang diusulkan :

\subsection{Fase 0 : Penerapan Konteks dan Ruang Lingkup}

\subsubsection{Identifikasi Masalah}

Berdasarkan hasil wawancara dan pengamatan berikut masalah yang dihadapi SMK Bina Nusantara Ungaran :

1. Sebagian bisnis belum menerapkan sistem informasi sehingga terjadi ketidakselarasan antar proses bisnis

2. Kurangnya koordinasi mengenai data.

3. Infrasktruktur yang kurang menunjang.

\subsubsection{Analisa Lingkungan Eksternal Bisnis}

Dalam menganalisa lingkungan eksternal bisnis dalam penelitian ini, tools yang digunakan adalah Porter's Five Forces. Fungsi dari analisa Five Forces ini adalah memetakan hal yang berasal dari eksternal organisasi yang dapat mempengaruhi jalannya proses bisnis yang memiliki dampak secara langsung maupun tidak langsung. Berikut hasil dari analisis Five Forces yang ada di SMK Bina Nusantara Ungaran pada gambar 2.

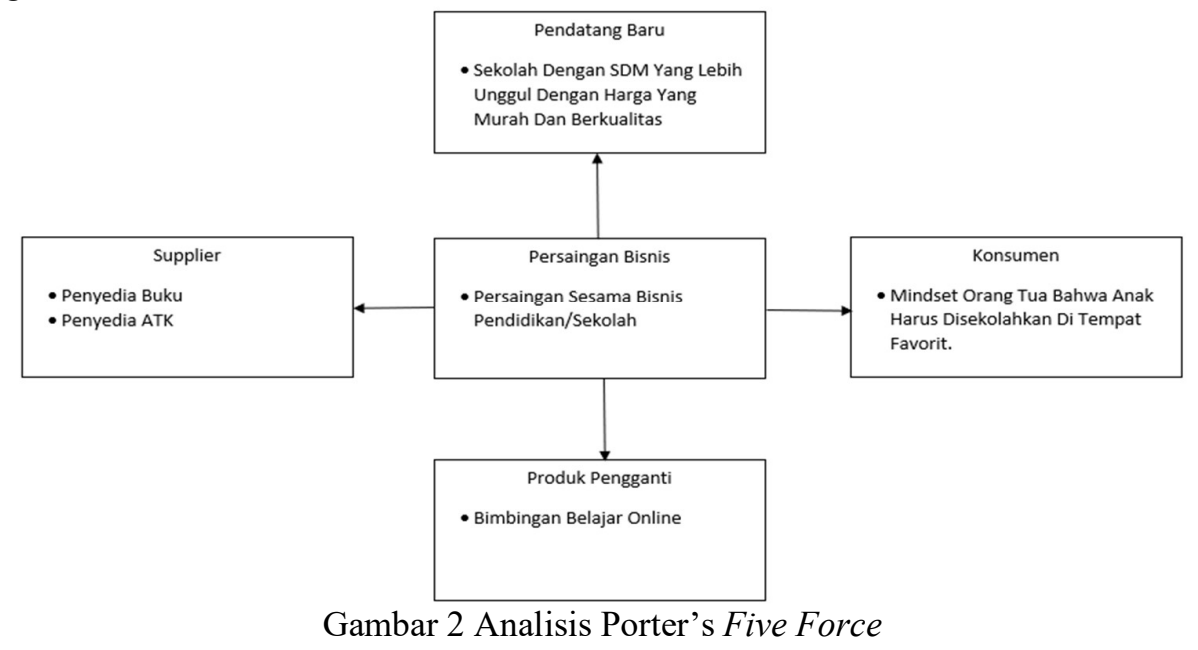

3.1.3 Analisa Lingkungan Internal Bisnis 
Dalam menganalisa lingkungan internal bisnis, tools yang digunakan adalah Analisa SWOT dan Porter's Value Chain yang sering digunakan oleh peneliti lain.

Berdasarkan hasil wawancara dari narasumber SMK Bina Nusantara Ungaran, maka dapat diidentifikasikan faktor SWOT. Selanjutnya Analisa tersebut dapat menjadi acuan strategi pemecahan permasalahan bisnis organisasi tersebut. Berikut hasil Analisa SWOT dapat dilihat pada tabel 1.

Tabel 1 Matriks Analisis SWOT.

\begin{tabular}{|c|c|}
\hline STRENGH & WEAKNESS \\
\hline $\begin{array}{l}\text { - Lokasi sekolah yang strategis di tengah ibukota } \\
\text { kabupaten semarang. } \\
\text { - Memiliki finansial yang cukup baik sehingga } \\
\text { dapat megembangkan bisnis perusahaan di } \\
\text { sekolah. } \\
\text { - Memiliki sumber daya manusia serta sarana- } \\
\text { prasarana untuk mendukung dalam aktivitas bisnis } \\
\text { perusahaan di sekolah. } \\
\text { - Memiliki jurusan yang berkompeten untuk } \\
\text { mendukung penerapan Sistem Informasi sesuai } \\
\text { yang dibutuhkan oleh sekolah tersebut. }\end{array}$ & $\begin{array}{l}\text { - Sistem informasi di sekolah belum } \\
\text { saling terintergrasi satu sama lain } \\
\text { sehingga mengakibatkan data-data } \\
\text { yang dimiliki tidak tertata dengan baik. }\end{array}$ \\
\hline OPPORTUNITY & THREATS \\
\hline $\begin{array}{l}\text { - Perkembangan teknologi informasi yang semakin } \\
\text { pesat dan modern serta ketersediaan aplikasi } \\
\text { enterprise yang dapat langsung digunakan tanpa } \\
\text { perlu mengembangkan. } \\
\text { - Peningkatan jumlah lulusan yang diterima di } \\
\text { perusahaan yang bekerja sama dengan sekolah. } \\
\text { - Peningkatan jumlah sumber daya manusia dalam } \\
\text { bidang pendidikan. }\end{array}$ & $\begin{array}{l}\text { - Kalah bersaing dengan pesaing yang } \\
\text { sudah memiliki sistem informasi yang } \\
\text { saling terintergrasi yang membuat } \\
\text { proses bisnis menjadi sangat efisien } \\
\text { dan cepat. } \\
\text { - Munculnya bimbingan belajar online } \\
\text { yang lebih mudah dan efisien. } \\
\text { - Sistem informasi yang sudah usang. }\end{array}$ \\
\hline
\end{tabular}

Fungsi analisa value chain ini adalah memetakan aktifitas proses bisnis internal yang dilakukan oleh organisasi SMK Bina Nusantara Ungaran baik dari aktifitas utama maupun aktifitas pendukung yang nantinya dapat mengetahui kebutuhan aplikasi untuk menunjang aktifitas tersebut. Berikut hasil analisis value chain yang terdapat pada gambar 3.

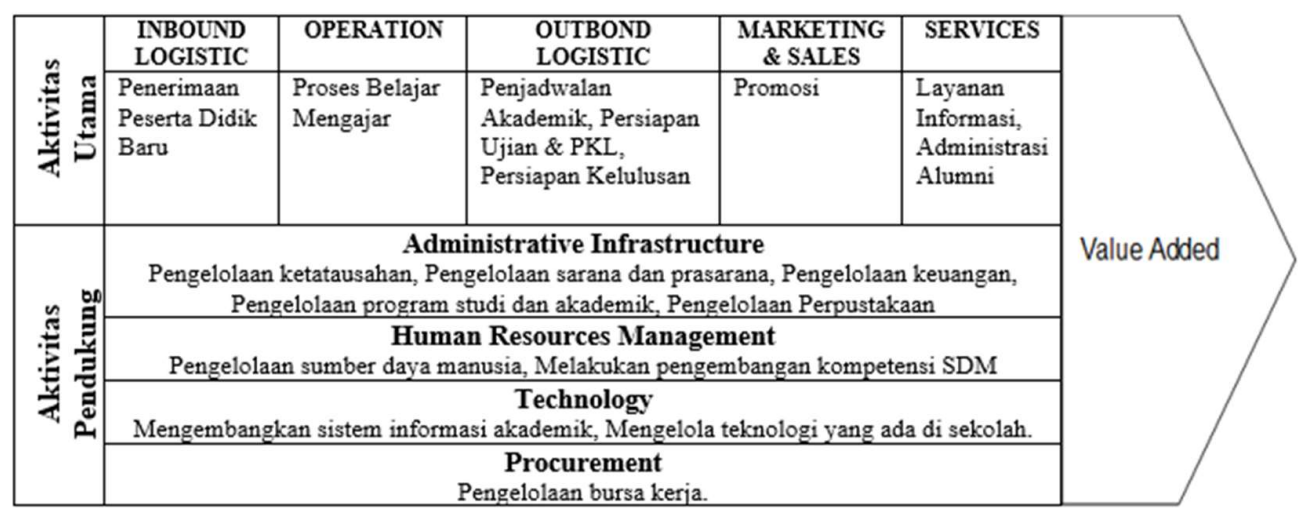

Gambar 3 Value Chain Analysis 


\subsection{Fase 1 : Menentukan Kebutuhan Informasi dan Pendukung}

3.2.1 Mengidentifikasi Informasi Organisasi

Dengan mengindetifikasi informasi Organisasi dapat mengetahui keselarasan visi dan misi dengan tujuan Organisasi yang ingin dicapai.

a. Visi : Mempersiapkan Pekerja Terampil Menengah yang Siap Berkompetisi dan Siap Bekerja.

b. Misi :

1. Mempersiapkan lulusan yang siap mengisi dunia kerja sesuai dengan bidang profesinya

2. Meningkatkan kemampuan wirausaha

3. Menyiapkan ketrampilan sesuai jurusan.

c. Tujuan :

1. Menghasilkan tenaga-tenaga yang terampil dan memiliki kemampuan yang kuat dalam mengelola.

2. bertujuan berwirausaha dan menaiki tangga permasalahan yang muncul di masyarakat dan bertaqwa kepada Tuhan Yang Maha Esa.

3. Memberi kesempatan kepada anak bangsa untuk memperoleh pendidikan yang layak sehingga dapat menjadi putra / putri bangsa yang terbaik.

\subsubsection{Mengidentifikasi Faktor Kesuksesan}

Tujuan Analisa ini adalah untuk menentukan serta mengevaluasi akan kebutuhan sistem informasi bisnis dan solusi strategis aplikasi dan database serta mengidentifikasikan peluang kesuksesan dalam perencanaan sistem informasi [6]. Berikut pemetaan CSF dapat dilihat pada tabel 2.

Tabel 2 Pemetaan Critical Success Factor

\begin{tabular}{|l|l|}
\hline Peluang (Opportunity) & Faktor Kesuksesan \\
\hline $\begin{array}{l}\text { Perkembangan teknologi informasi yang semakin } \\
\text { pesat dan modern serta ketersediaan aplikasi } \\
\text { enterprise yang dapat langsung digunakan tanpa perlu } \\
\text { mengembangkan. }\end{array}$ & $\begin{array}{l}\text { Dibangunnya sistem informasi yang } \\
\text { menunjang aktifitas bisnis sesuai dengan } \\
\text { kebutuhan. }\end{array}$ \\
\hline Lingkungan bisnis sekolah yang terus berkembang. & $\begin{array}{l}\text { Peningkatan kinerja layanan dibidang } \\
\text { Pendidikan. }\end{array}$ \\
\hline Peningkatan kualitas sekolah. & $\begin{array}{l}\text { Meningkatnya kepercayaan masyarakat } \\
\text { terhadap sekolah swasta. }\end{array}$ \\
\hline $\begin{array}{l}\text { Peningkatan jumlah lulusan yang diterima di } \\
\text { perusahaan yang bekerja sama dengan sekolah. }\end{array}$ & $\begin{array}{l}\text { Jumlah lulusan yang diterima di dunia } \\
\text { kerja meningkat. }\end{array}$ \\
\hline $\begin{array}{l}\text { Peningkatan jumlah sumber daya manusia dalam } \\
\text { bidang pendidikan. }\end{array}$ & $\begin{array}{l}\text { Tersedianya sumber daya manusia yang } \\
\text { berkompeten. }\end{array}$ \\
\hline
\end{tabular}

\subsection{Fase 2 : Evaluasi Kesesuain Kebutuhan Bisnis Dengan Sistem Yang Sudah Ada}

Dari hasil analisa value chain dari SMK Bina Nusantara Ungaran, kemudian ditentukannya sistem informasi yang berpeluang untuk mendukung aktifitas proses bisnis yang ada di value chain tersebut. Berikut hasil analisa terkait kondisi sistem informasi berdasarkan value chain saat ini yang dapat dilihat di tabel 3 dan tabel 4.

Tabel 3 Sistem informasi berdasarkan value chain aktifitas utama.

\begin{tabular}{|l|l|c|}
\hline \multicolumn{1}{|c|}{ Value Chain } & Kegiatan & Sistem Saat Ini \\
\hline Inbound Logistic & Melakukan pendaftaran calon siswa. & - \\
\hline
\end{tabular}




\begin{tabular}{|l|l|c|}
\hline Operation & $\begin{array}{l}\text { Melakukan kegiatan proses belajar } \\
\text { mengajar. }\end{array}$ & - \\
\hline Outbond Logistic & $\begin{array}{l}\text { Melakukan Persiapan Ujian, PKL, dan } \\
\text { Kelulusan }\end{array}$ & - \\
\hline Marketing \& Sales & $\begin{array}{l}\text { Melakukan promosi baik offline maupun } \\
\text { online (sosial media). }\end{array}$ & Instagram \\
\hline Services & $\begin{array}{l}\text { Melakukan Layanan Informasi Sekolah } \\
\text { dan Administrasi Alumni }\end{array}$ & - \\
\hline
\end{tabular}

Tabel 4 Sistem informasi berdasarkan value chain aktifitas pendukung.

\begin{tabular}{|l|l|c|}
\hline \multicolumn{1}{|c|}{ Value Chain } & \multicolumn{1}{|c|}{ Kegiatan } & Sistem Saat Ini \\
\hline Administrative Infrastructure & $\begin{array}{l}\text { Pengelolaan keuangan sekolah,Pengurusan } \\
\text { administrasi ketatausahaan sekolah, } \\
\text { pengelolaa sarana dan prasarana, } \\
\text { pengelolaan program studi dan akademik }\end{array}$ & $\begin{array}{c}\text { Dapodik, SI } \\
\text { Penggajian }\end{array}$ \\
\hline $\begin{array}{l}\text { Human } \\
\text { Management } \quad \text { Resources }\end{array}$ & $\begin{array}{l}\text { Mengelola sumber daya manusia, } \\
\text { Melakukan pengembangan kompetensi } \\
\text { SDM. }\end{array}$ & $\begin{array}{c}\text { SI Absensi } \\
\text { (Fingerprint) }\end{array}$ \\
\hline Technology & Mengelola dan Mengembangkan SI/TI & - \\
\hline Procurement & Pengelolaan perpustakaan & - \\
\hline
\end{tabular}

Untuk mendapatkan gambaran dari sistem informasi apa saja yang digunakan serta kontribusi dari setiap aplikasi yang digunakan untuk menunjang proses bisnis saat ini maka semua aplikasi dipetakan meggunakan model McFarlan's Strategic Grid yang dapat dilihat di table 5 berikut.

Tabel 5 Portfolio aplikasi saat ini.

\begin{tabular}{|c|c|}
\hline STRATEGIC & HIGH POTENTIAL \\
\hline & $\bullet \quad$ SI Penggajian \\
& $\bullet \quad$ SI Absensi (Fingerprint) \\
\hline Instagram (Sosial Media) & \\
$\bullet \quad$ DAPODIK & \\
\hline KEY OPERATIONAL & SUPPORT \\
\hline
\end{tabular}

Berdasarkan hasil analisis dengan tools diatas dapat disimpulkan bahwa SMK Bina Nusantara Ungaran belum sepenuhnya menerapkan sistem aplikasi yang strategis dalam proses bisnisnya untuk menunjang persaingan di masa mendatang dilihat dari beberapa sektor tidak memiliki sistem atau aplikasi.

\subsection{Fase 3 : Menentukan Solusi Strategi}

3.4.1 Analisa Kebutuhan Informasi

Kebutuhan dari setiap divisi dapat ditentukan dari Analisa CSF melalui tujuan tiap devisi masingmasing [6]. Kemudian setiap CSF dievaluasi serta disesuaikan dengan rumusan strategi yang dihasilkan dari analisis SWOT. Berikut hasil kebutuhan informasi SMK Bina Nusantara Ungaran pada aktifitas utamanya pada tabel 6 . 
Tabel 6 Analisis Kebutuhan Informasi

\begin{tabular}{|l|l|l|l|}
\hline Tujuan Divisi & CSF & Value Chain & Kebutuhan Informasi \\
\hline $\begin{array}{l}\text { Mempromosikan kepada } \\
\text { orang tua mengenai } \\
\text { profil sekolah. }\end{array}$ & $\begin{array}{l}\text { Meningkatnya } \\
\text { jumlah orang tua } \\
\text { mengetahui akan } \\
\text { profil sekolah. }\end{array}$ & $\begin{array}{l}\text { Marketing \& } \\
\text { Sales }\end{array}$ & Laporan informasi PPDB. \\
\hline $\begin{array}{l}\text { Peningkatan jumlah } \\
\text { pendaftar calon peserta } \\
\text { didik baru }\end{array}$ & $\begin{array}{l}\text { Meningkatnya } \\
\text { jumlah pendaftar } \\
\text { calon peserta didik } \\
\text { baru }\end{array}$ & $\begin{array}{l}\text { Inbound } \\
\text { Logistic }\end{array}$ & $\begin{array}{l}\text { Data calon peserta didik } \\
\text { baru, } \\
\text { Data peningkatan jumlah } \\
\text { pendaftar. }\end{array}$ \\
\hline $\begin{array}{l}\text { Menyediakan fasilitas } \\
\text { yang mendukung proses } \\
\text { bisnis dengan handal.. }\end{array}$ & $\begin{array}{l}\text { Tersediannya } \\
\text { fasilitas } \\
\text { mendukung proses } \\
\text { bisnis dengan baik. }\end{array}$ & $\begin{array}{l}\text { Operation, } \\
\text { Outbond } \\
\text { Logistic }\end{array}$ & $\begin{array}{l}\text { Informasi data PKL, ujian, } \\
\text { kelulusan dan proses } \\
\text { belajar mengajar. }\end{array}$ \\
\hline $\begin{array}{l}\text { Menyediakan informasi } \\
\text { sekolah yang akurat } \\
\text { untuk masyarakat dan } \\
\text { alumni }\end{array}$ & $\begin{array}{l}\text { Meningkatnya } \\
\text { jumlah orang akan } \\
\text { informasi sekolah. }\end{array}$ & Services & $\begin{array}{l}\text { Data informasi layanan } \\
\text { sekolah dan alumni. }\end{array}$ \\
\hline $\begin{array}{l}\text { Menyediakaan informasi } \\
\text { mengenai } \\
\text { sekolah. }\end{array}$ & $\begin{array}{l}\text { Tersedianya daternal } \\
\text { informasi mengenai } \\
\text { internal sekolah guna } \\
\text { menjalankan proses } \\
\text { bisnis. }\end{array}$ & $\begin{array}{l}\text { Administrative } \\
\text { Infrastructure, } \\
\text { Resources } \\
\text { Management, } \\
\text { Procurement }\end{array}$ & $\begin{array}{l}\text { Data keuangan, data data pegawai, data } \\
\text { serpustakaan, data bursa } \\
\text { kerja. }\end{array}$ \\
\hline
\end{tabular}

\subsubsection{Menentukan Solusi Aplikasi dan Basis Data}

Dalam menentukan strategi yang akan digunakan pada fase ini dapat dilakukan dengan melihat tren yang berada dipasaran serta digunakan oleh banyak organisasi atau perusahaan [3][7]. Hal yang menjadi perhatian adalah tren jaringan, tren aplikasi dan basis data, serta tren keamanan sistem informasi dan teknologi. Berikut strategi aplikasi yang dapat dilihat pada table 7.

Tabel 7 Solusi Strategi Aplikasi dan Basis Data

\begin{tabular}{|l|l|l|}
\hline Tren Jaringan & \multicolumn{2}{l}{$\begin{array}{l}\text { Internet, Wireless } \\
\text { Intranet }\end{array}$} \\
\hline Tren Aplikasi dan Basis Data & $\begin{array}{l}\text { Java, }, \\
\text { Phyton,PHP, } \\
\text { ERP/SAP }\end{array}$ & SQL Server,MySQL, \\
& Oracle 19c \\
\hline Tren Keamanan SI/TI & $\begin{array}{l}\text { Authentikasi, Enkripsi, Firewall, Kebijakan } \\
\text { Keamanan }\end{array}$ \\
\hline
\end{tabular}

\subsubsection{Menentukan Solusi SI/TI}

Didalam menentukan solusi aplikasi untuk mendukung proses bisnis SMK Bina Nusantara Ungaran, didapat dari analisis value chain dengan membandingkan SI/TI saat ini yang menghasilkan portofolio aplikasi future yang dapat dilihat di tabel 8 .

Tabel 8 Portofolio Aplikasi Future SMK Bina Nusantara Ungaran.

\begin{tabular}{|l|c|l|}
\hline Value Chain & Aplikasi Saat Ini & Aplikasi Usulan \\
\hline Inbound Logistic & - & SI PPDB \\
\hline Operational & - & E-Learning \\
\hline Outbond Logistic & - & SI Kesiswaan \\
& & SI Prakerin \\
& & SI Kelulusan \\
\hline
\end{tabular}




\begin{tabular}{|l|l|l|}
\hline Marketing \& Sales & Instagram & Website Company Profile \\
\hline Services & \multicolumn{1}{|c|}{-} & $\begin{array}{l}\text { SI Bursa Kerja } \\
\text { SI Alumni }\end{array}$ \\
\hline Administrative Infrastructure & $\begin{array}{l}\text { Dapodik } \\
\text { SI Penggajian }\end{array}$ & $\begin{array}{l}\text { SI Kurikulum } \\
\text { SI Keuangan dan SPP } \\
\text { SI Inventori }\end{array}$ \\
\hline Human Resources Management & SI Absensi (Fingerprint) & SI Kepegawaian \\
\hline Technology & \multicolumn{1}{|c|}{-} \\
\hline Procurement & - & SI Perpustakaan \\
\hline
\end{tabular}

\subsection{Fase 4 : Menyiapkan dan Melakukan Rencana Implementasi}

3.5.1 Menetapkan Skala Prioritas

Berdasarkan usulan sistem informasi yang telah dibuat, maka akan dipetakan kedalam model McFarlan's Strategic Grid guna mengetahui skala prioritas dalam pengimplementasian oleh SMK Bina Nusantara Ungaran di kemudian hari. Berikut hasil pemetaan aplikasi dengan model McFarlan's Strategic Grid dapat dilihat pada tabel 9.

Tabel 9 Portofolio Aplikasi Usulan model McFarlan's Strategic Grid

\begin{tabular}{|c|c|c|c|}
\hline \multicolumn{2}{|l|}{ STRATEGIC } & \multicolumn{2}{|l|}{ HIGH POTENTIAL } \\
\hline $\begin{array}{ll} & \text { Instagram } \\
\text { - Website Company Profile }\end{array}$ & $\begin{array}{l}\text { Ada } \\
\text { Baru }\end{array}$ & $\begin{array}{ll}\text { - } & \text { SI Kesiswaan } \\
\text { - } & \text { SI Kelulusan } \\
\text { - } & \text { SI Perpustakaan } \\
\text { - } & \text { SI Penggajian } \\
\text { - } & \text { SI Absensi }\end{array}$ & $\begin{array}{l}\text { Baru } \\
\text { Baru } \\
\text { Baru } \\
\text { Baru } \\
\text { Ada }\end{array}$ \\
\hline $\begin{array}{ll} & \text { DAPODIK } \\
\text { - } & \text { SI PPDB } \\
\text { - } & \text { E-Learning } \\
\text { - } & \text { SI Keuangan dan SPP } \\
- & \text { SI Kurikulum } \\
\text { - } & \text { SI Kepegawaian } \\
\text { - } & \text { SI Prakerin } \\
\end{array}$ & $\begin{array}{l}\text { Ada } \\
\text { Baru } \\
\text { Baru } \\
\text { Baru } \\
\text { Baru } \\
\text { Baru } \\
\text { Baru } \\
\text { Baru }\end{array}$ & $\begin{array}{ll}\text { - } & \text { SI Alumni } \\
\text { - } & \text { SI Bursa Kerja }\end{array}$ & $\begin{array}{l}\text { Baru } \\
\text { Baru }\end{array}$ \\
\hline KEY OPERATIONAL & & \multicolumn{2}{|l|}{ SUPPORT } \\
\hline
\end{tabular}

\subsubsection{Rencana Implementasi}

Berdasarkan hasil pemetaan skala prioritas menggunakan McFarlan's Strategic Grid diatas, dapat dibuat rencana implementasi sistem informasi yang diusulkan pada table 10 berikut ini :

Tabel 10 Rencana Implementasi

\begin{tabular}{|c|c|c|c|c|c|}
\hline \multirow{2}{*}{\multicolumn{6}{|c|}{$\begin{array}{l}\text { Solusi SI/TI } \\
\text { SI PPDB }\end{array}$}} \\
\hline & & & & & \\
\hline \multicolumn{6}{|l|}{ E-Learning } \\
\hline \multicolumn{6}{|l|}{ SI Keuangan dan SPP } \\
\hline \multicolumn{6}{|l|}{ SI Kurikulum } \\
\hline \multicolumn{6}{|l|}{ SI Kepegawaian } \\
\hline \multicolumn{6}{|l|}{ SI Prakerin } \\
\hline \multicolumn{6}{|l|}{ SI Inventori } \\
\hline Website Company Profile & & & STRATEGIC & & \\
\hline
\end{tabular}




\begin{tabular}{|c|c|}
\hline \multirow{2}{*}{$\begin{array}{l}\text { SI Kesiswaan } \\
\text { SI Kelulusan }\end{array}$} & \multirow{4}{*}{ HIGH POTENTIAL } \\
\hline & \\
\hline SI Perpustakaan & \\
\hline SI Penggajian & \\
\hline SI Alumni & \\
\hline SI Bursa Kerja & \\
\hline
\end{tabular}

\section{KESIMPULAN}

Berdasarkan hasil observasi serta analisa dapat disimpulkan bahwa SMK Bina Nusantara Ungaran sudah menerapkan sistem informasi, sistem tersebut cukup membantu dalam proses bisnis yang dilakukan. Namun ada beberapa divisi yang belum menerapkan sistem informasi. Dengan demikian perumusan rencana strategi SI/TI dengan metode versi tozer serta tools untuk mendukung analisa seperti Value Chain, Five Force, SWOT, CSF, McFarlan's Strategic Grid. Menghasilkan sebuah portofolio aplikasi untuk memberikan gambaran dalam penerapan SI/TI guna menyelaraskan strategi bisnis dan visi misi yang ingin dituju. Jika portofolio SI/TI diterapkan oleh SMK Bina Nusantara Ungaran diharapkan dapat memberi manfaat bagi proses bisnis sehingga dapat meningkatkan kualitas layanan dan organisasi dapat berkembang.

\section{DAFTAR PUSTAKA}

[1] Ward, J and Pepard Joe, 2002, Strategic Planning for Information Systems (3rd Edition), John Wiley \&Sons Ltd, England.

[2] Tozer, E.E., 1996, Strategic IS/IT Planning : Professional series, Butterworth-Heinemann, United States.

[3] W. Andri and A. Arif, 2014,"Penerapan Metodologi Tozer Dalam Perencanaan Strategis Si/Ti Pada Sekolah Tinggi Teknik Musi”, Journal of Information Systems, vol. 9, no. 2, pp. 95-100.

[4] W. Andri, 2011, "Perencanaan Strategis SI/TI Pada Perusahaan Otomotif Dengan Menggunakan Metodologi Tozer," Karya Akhir, Magister Teknologi Informasi, Universitas Indonesia, Jakarta.

[5] I. Windi, 2016, "Perencanaan Strategis Si/Ti Pada Dinas Cipta Karya, Tata Ruang Dan Kebersihan Kabupaten Kubu Raya Dengan Menggunakan Metodologi Tozer", Journal SpeedSentra Penelitian Engineering dan Edukasi, Volume 8, No 1.

[6] P. Widyaningsih, M. Mustafid, and A. Rochim, 2014, "Perencanaan Strategis Sistem Informasi Pada Institusi Pendidikan Tinggi Menggunakan Analisis Critical Success Factors", JSINBIS (Jurnal Sistem Informasi Bisnis), vol. 1, no. 2, pp. 86-92.

[7] H. Tri, 2017, "Planning Of Tozer Methodology Master Plan In Educational Of Information And Communication Technology (A Case Study At PT Pesona Edu Solution Jakarta)",Jurnal Teknik dan Komputer (JTIK), Vol. 06 No. 22. 